UDC 378.046.4

DOI: $10.17223 / 24109266 / 8 / 11$

\title{
FOREIGN LANGUAGE TEACHERS' TRAINING IN THE SYSTEM OF CONTINUING EDUCATION
}

\author{
P.V. Sysoyev \\ Derzhavin Tambov State University, Moscow Pedagogical State University \\ (Tambov, Moscow, Russian federation) \\ E-mail: psysoyev@yandex.ru
}

\begin{abstract}
Nowadays Russian universities offer applicants three linguistics and philology majors: "Philology" (profile "Foreign Philology"), "Linguistics" and "Teacher Education" (profile "Foreign Language"). However, which of them fully prepares students to become teachers of foreign languages. In this paper, the author gives an analysis of the situation in the national education system in the undergraduate, graduate and post-graduate continuing education and offers an individual education path "bachelor-master-graduate school" for training foreign language teachers.

Keywords: continuing education; methodical preparation; the preparation of teachers of foreign languages; a three-level model of training specialists.
\end{abstract}

\section{Importance}

On the modern education market universities offer a range of majors of different levels (undergraduate, graduate, post-graduate) related to foreign language training as specialization ("Philology", "Linguistics", "Teacher Education"), using all possible arguments to attract applicants. Moreover, the transition to a two- or three-level model of training (undergraduate, graduate and postgraduate) de jure creates conditions for the implementation of continuing education on an individual path, allowing to take into account students' individual professional interests and needs to the full. Thus, having received a bachelor's degree in one major, student can continue education in the same major, or select another one, which fully meet the student's demands, interests, and needs. However, how to understand what chain of the "undergraduate-graduate- postgraduate" meets best the needs of students who want to become foreign language teachers in secondary and higher education establishments? The purpose of this paper is the author's attempt to show a variety of options for getting foreign language teacher education in Russian universities and to define the chain of continuing education, which would meet the social demand for teacher training in a foreign language to the full (In this paper we adhere to the definition of "language education" proposed by B.S. Gershunsky, for whom language education is a "value, process, result and system of foreign language teaching" [as a specialization] [1:38].). 


\section{Historical background}

In the USSR the training of foreign language teachers was conducted in pedagogical institutes or universities, pedagogical schools and colleges. In universities standard period of training in major "Foreign Language" lasted 5 years. At the end of training students received qualification "Teacher of a foreign language" or "Teacher of foreign languages". This qualification allowed graduates to be employed as foreign language teachers in secondary schools, institutions of secondary special and vocational education, universities. In addition, theoretical and practical training allowed graduates to work as interpreters, even though there were specialized institutions of higher education. At the same time, it is necessary to emphasize that in the USSR the basic need in the professionals who speak foreign languages was mainly in the field of education. That is why the main emphasis in language education in the country was reasonably placed on pedagogical training in a field of foreign languages. As a result, in most regions of the country there were pedagogical institutes or universities with faculties of foreign languages to meet the needs of each region in the teachers. In addition, in the USSR and Russia there was a whole network of pedagogical colleges which gradually merged into universities or transformed into pedagogical colleges. In these establishments students received the secondary special and vocational education allowing to work as foreign language teachers in the lower grades of secondary schools, institutions of secondary vocational and special education.

The mid-1990's were characterized by global changes in the Russian system of higher education. In most regions of Russia establishment of classical universities by merging pedagogical institutes with other institutions (e.g. Institute of Culture, etc.) led to a gradual shift from "pedagogical" to "classical" specializations. In particular, instead of foreign language teacher training many universities switched to training of philologists who could speak foreign languages. The changes were made not only the names of the specializations, but, more importantly, the content of the teaching. From educational programs and curricula of specialization of "Philology" (and then major "Philology" profile "Foreign Philology") in many universities were excluded such important disciplines for pedagogical activities as "Developmental Psychology", "Educational Psychology", "Didactics", "Theory of teaching", "Foreign Language Textbook", "Foreign language teaching methodology", although the last one remained the only pedagogical discipline of curriculum in many universities of country (major "Philology"). They were replaced by new theoretical courses, many of them, according to the contents, represented regional philological research schools, and were not directly aimed at an intensification and modernization of students' training for pedagogical activity (Notice that I do not detract from the significance of many philological disciplines. I am just state the fact that their in- 
clusion in curricula often occurred to the prejudice of disciplines of psychopedagogical orientation.). At the same time, the main place of employment of graduates of foreign language specializations in the majority of regions of the country were and still are secondary schools and other educational institutions. Thus, we can say that in some regions of country where population need in training of pedagogical staff holding the foreign language teaching methods at different stages, the authority of the universities deliberately ignored the social order in favor of the prevailing trend.

Just a few classical universities in the country preserved pedagogical specializations and at the same time developed philological/linguistic and teacher education in the field of foreign languages. For the sake of justice it should be noted that a big contribution to preservation of specialization in order to train foreign language teachers was made by the Moscow State Linguistic University, which initiated the appearance of the specialization "Theory and Methods of Teaching Foreign Languages and Cultures" (1996). In 2010 Moscow State Pedagogical University and Herzen Russian State Pedagogical University opened a new major "Teacher Education" where teachers of foreign languages are currently being prepared.

In 2011, in connection with the transition to a two-level system of training (undergraduate-post-graduate) many specializations, including the linguistics, moved to the majors. In accordance with the Federal State Educational Standards of Higher Vocational Education (2011) in many majors were allocated individual learning profiles, defining the sphere of future professional activity of graduates. In particular, in the major "Philology" training is conducted both in the field of Russian and in the field of foreign languages. For those who learned foreign language as a specialization, universities determined the profile "Foreign Philology" (in the standard selection of this profile is not provided). On major "Linguistics" the profiles "Theory and Methods of Teaching Foreign Languages and Cultures", "Translation and Theory of Translation", "Theory and Practice of Cross-cultural Communication", "Theoretical and Applied Linguistics", and in the major "Teacher Education" - the profile "Foreign Language" are allocated. Besides, "Teacher Education" is provided by the opportunity to study on two profiles (a two-profile undergraduate), for example "Foreign Language and History", or "Foreign Language and Foreign Language" (the second foreign language), etc. With such a great variety it is often quite difficult for an applicant to define what of these linguistics and philology majors fully prepare teachers and lecturers of a foreign language.

Consider federal regulations and exemplary curricula for abovementioned majors for undergraduate, graduate and post-graduate for further discussion of topical and controversial issues of methodical preparation of teachers of a foreign language in system of continuing education. 


\section{Preparation for pedagogical activity of graduates in regulations of the higher education of the undergraduate}

With the transition to a two-level model of education "bachelormaster" the qualification "Teacher" or "Lecturer" is no longer indicated in the bachelor's diplomas. Instead, it indicates the qualification "Bachelor" in the modern undergraduate diploma, the major and orientation (profile) of the educational program. This fact gives additional opportunities for manipulation of applicants who do not understand all the subtleties of the higher education system in the Russian Federation.

Federal Educational Standard of Higher Education regulates types of professional activity which will prepare the graduates who have mastered an educational program of undergraduate [2-7]. Readiness for each of types of professional activity is defined by the number of professional competences which are presented by types of professional activity in the standard. Note that the opportunity to prepare students for teaching activities inherent in modern Federal Educational Standard of Higher Education in all three majors (undergraduate level). In addition, linguistic and didactics preparation, designated in Federal Educational Standard of Higher Education for the major "Linguistics", allows students to master the theoretical issues of foreign language teaching (learning content, goals, objectives, principles, methods, means, language learning, methods of research, methodological foundations of language teaching). In this regard, N.D. Galskova justifiably calls Language didactics the "methodological basis of foreign languages teaching" [8: 81]. Linguistic and Didactic preparation will allow graduates to not only simulate correctly the pedagogical process of learning a foreign language at different stages, but also to determine the policy of language education in schools. However, the complexity and ambiguous interpretation of quality of methodical preparation of pedagogical staff is connected with an opportunity within each major for the aim of a narrow-profile specialization in specific types of professional activity of allocation of profiles of training.

Ideally, the choice of profile education should regulate and restrict the professional activities of students who have mastered the basic professional educational program (BPEP). In particular, teacher training appropriate to maintain within the profile "Applied Philology" (major "Philology") (provided that methodical program content) or "Theory and Methods of Teaching Foreign Languages and Cultures" (major "Linguistics"), but not to artificially add pedagogical activity in the profiles, which not originally designed for the training of teachers and lecturers (e.g. profiles "Foreign Philology" (Philology) or "Translation and Theory of Translation" (Linguistics)). Otherwise, the meaning of separation of training profiles within the majors is completely destroyed! In addition, Federal Educational Standard of Higher Education does not regulate the minimum amount of labor input re- 
quired for the formation of a group of competences (in particular, related to teaching activities). The standard requirement is only presented to the volume of the disciplines of basic and variable parts. The number of disciplines and their labor input which need to prepare students for a specific type of professional activity is not specified in the standard. Such a gap in the regulations allows the authors and developers of basic professional educational program in specific schools to declare about the training of teachers and foreign language teachers including a 1-3 insignificant complexity of educational disciplines of psychological and pedagogical and methodological orientation in the curricula. In this regard, in the existing regulatory and legal framework of Federal Educational Standard of Higher Education for more accurate orientation of applicants in a variety of advertised linguistics and philology majors, it could be only recommended to study basic professional educational programs and curricula offered profile training and determine which of them to a greater extent creates didactic conditions to prepare for future careers in the field of foreign language teaching. Let me illustrate the presence of disciplines of psychological and pedagogical orientation of some of the curricula in three profiles of the three majors (Table).

Psychological and pedagogical orientation disciplines in the curricula of profiles for undergraduate

\begin{tabular}{|c|c|c|c|}
\hline Major and profile & $\begin{array}{c}\text { Major "Philology", } \\
\text { profile "Foreign } \\
\text { philology" }\end{array}$ & $\begin{array}{l}\text { Major "Linguistics", } \\
\text { profile "Theory and } \\
\text { Methods of Teaching } \\
\text { Foreign Languages } \\
\text { and Cultures" }\end{array}$ & $\begin{array}{l}\text { Major Teacher, } \\
\text { profile "Foreign } \\
\text { languages" }\end{array}$ \\
\hline \begin{tabular}{|l|} 
Discipline \\
Curriculum
\end{tabular} & $\begin{array}{l}\text { - Psychology and } \\
\text { pedagogy } \\
\text { - Methods of teaching } \\
\text { a foreign language at } \\
\text { school } \\
\text { - Teaching practice }\end{array}$ & $\begin{array}{l}\text { - Psychology } \\
\text { - Pedagogy } \\
\text { - Theory of training } \\
\text { - Methods of teaching } \\
\text { a foreign language and } \\
\text { culture at different } \\
\text { stages of learning } \\
\text { - Information technol- } \\
\text { ogies in training of } \\
\text { foreign language } \\
\text { - Modern training and } \\
\text { methodology complex } \\
\text { in foreign language } \\
\text { - Teaching practice }\end{array}$ & $\begin{array}{l}\text { - General Psychology } \\
\text { - Developmental psy- } \\
\text { chology } \\
\text { - Pedagogical psy- } \\
\text { chology } \\
\text { - General pedagogy } \\
\text { - History of Pedagogy } \\
\text { and Education } \\
\text { - Modern educational } \\
\text { technology } \\
\text { - Methods of teaching } \\
\text { foreign languages and } \\
\text { cultures at different } \\
\text { stages of learning } \\
\text { - Information and } \\
\text { communication tech- } \\
\text { nologies in linguistics } \\
\text { - Learning theory } \\
\text { - Teaching practice }\end{array}$ \\
\hline
\end{tabular}

Analysis of the curricula for the presence of disciplines of psychological and pedagogical orientation suggests that the preparation of teachers and 
foreign language teachers can fully be conducted in major "Linguistics" (profile "Theory and Methods of Teaching Foreign Languages and Cultures" and "Teacher Education" (profile "Foreign Language"). Certainly, in different educational institutions all over the country the number of disciplines of psychological and pedagogical orientation and their labor input can differ in the direction of increasing and decreasing. In this paper, we deliberately do not specify the schools whose curricula were used to compile Table, since a similar situation can be observed in various regions of the country. We only pay attention of the teaching community to the current trend of inconsistency between the stated aim of preparing students for teaching activities in teaching on a particular profile and the number of disciplines of psychological and pedagogical orientation and their labor input in the curricula for training the selected profile. Is it possible to fully prepare students to work in a secondary school in the presence of only two courses in pedagogy and psychology and methods of teaching a foreign language in the curriculum (the amount of these courses will remain outside of this article)? At the same time, our criticism is not related to the curricula in "Philology", including the list of disciplines of psychological and pedagogical orientation, similar curricula in "Linguistics" and "Teacher education".

It is necessary to mention experience of Derzhavin Tambov State University where in the curricula for teacher education (profile "Foreign Language") present the disciplines which both aimed at the formation of foreign language communicative competence and methodical competence of students. For example, during the course "The use of the audio-visualization in learning of language and culture", the students watch and discuss language foreign films, and on the methodological side, they analyze and develop their methods of teaching foreign languages and cultures on the basis of films as well.

A model of preparation of undergraduate students in profile "Teacher Education" deserves special attention, it implements by some universities where, regardless of the profile of education, during the first two years students of different learning profiles ("Foreign Language", "History", "Preschool Education", "Elementary Education", etc.) study the same range of disciplines of psychological and pedagogical orientation ("Child Psychology", "Developmental Psychology", "Educational Psychology", "Developmental Anatomy and Physiology", "Developing Training the Child to School", "Methods of Teaching and Education of Pre-school Children", "Methods of Teaching and Education of Younger Pupils", etc.). Thus, students receive unique wide-profile training through educational activities, and they will be qualified to teach their subjects at different stages of education. Particular relevance this model acquires in regions where opportunities of employment in the specialization are considerably limited in comparison with megalopolises. 


\section{Training of teachers and foreign language teachers in graduate and post-graduate}

One of the positive sides of a two-level education system is an opportunity to continue education in graduate on another profile or major. Unlike undergraduate where education is generally massive, graduate and postgraduate are focused on a smaller number of students who more consciously and deliberately choose a specific major and specific education program. Considering the opportunity of the pointed choice of the program according to specific needs of the region, there are no training profiles in the graduate. Instead of them ideally under several certain types of professional activity, the specific educational program is offered to applicants. Comparison of the Federal Educational Standard of Higher Education (undergraduate, graduate and post-graduate) indicates the presence of continuity in the regulations between the levels of education. At all levels and majors there is the opportunity to prepare students for teaching activities. The graduate and especially post-graduate focus on the research work, which is quite natural. Being the third level of education, post-graduate prepares pedagogical staff for higher education.

As in the undergraduate, readiness for every type of professional work in the graduate is determined by the formation of a number of components of professional competencies, which are presented in the standard for the type of professional activity. However, unlike the undergraduate which has a broader focus on the professional activities of future graduates, heads of graduate and post-graduate have a little more freedom to determine the activities which will prepare the basic professional educational program.

Master's program is developed with a focus on research and/or kind of pedagogical professional activity. In accordance with the professional activities, the most optimal conditions for training teachers in the field of foreign language teaching create master's programs in applied philology, linguistics and teacher education, including discipline aimed at both the formation of foreign language communicative competence (C1-C2 levels) and competence in the field of methodology of teaching foreign languages and cultures. Master's program author has the freedom to choose the name of the program which should ideally respond to its content. In practice, graduates of the bachelor degree programs are often offered education programs which do not meet the requirements of the level of preparation of graduates of master's program and unable to prepare for the educational activities in the field of foreign language. Firstly, some curricula do not contain or contain the minimal labor input for the further study of a foreign language. By doing this, developers of education programs ignore the fact that in the graduate of foreign language major students must achieve a $\mathrm{C} 1-\mathrm{C} 2$ level language skills. The transition from level $\mathrm{B} 2 / \mathrm{C} 1$ to $\mathrm{C} 1 / \mathrm{C} 2$ requires 
200 academic hours. Secondly, the curriculum in the graduate must contain a considerable amount of disciplines of psychological and pedagogical orientation, many of which should reflect the specifics of higher education by their content (for example: "Methods of Foreign Language Teaching in Higher Education"). In this context, choosing a master's program, the applicant must understand that the only one program corresponds to the interests which contains: a) a large amount of foreign language and b) a large amount of disciplines of psychological and pedagogical orientation. It should be advised for the applicants entered to graduate to read the description of the educational program for the presence of educational activities and study the curricula to determine the presence of language courses and psychological and pedagogical orientation.

Pedagogical activity in post-graduate has narrow-profiled character. Post-graduate in philological sciences provides the training in disciplines of a philological and linguistic orientation, in pedagogical sciences it is a technique of training in a foreign language at different stages. In accordance with the direction of the program, each university independently formulates a list of professional competencies formed as a result of the study of a particular cycle of disciplines. In our country there is a tradition to prepare candidates of Philological Sciences (Theory of Language, the Germanic Languages, Romance Languages, etc.) and Pedagogical Sciences (Theory and Methods of Teaching and Training (foreign languages)). In this regard, a special interest may represent post-graduate programs, including interdisciplinary modules which are implemented simultaneously in several majors. In particular, V.V. Safonova [9] presented in her paper a description of the innovative experience of the Faculty of Foreign Languages and Area Studies at Lomonosov Moscow State University to develop this interdisciplinary module on foreign language teaching methodology for post-graduate students studying in the majors of "Linguistics and Literature" and "Education and Pedagogical Science". I note that the practice of creating these modules is possible only in the teaching staff interested in improving the quality of education and competitiveness of graduates, rather than "to grab the biggest piece of the pie". In most universities of the country where at the same time students are offered "Philology", "Linguistics" and "Teacher education", for subjective reasons the development and introduction of interdisciplinary modules is not possible.

Thus, de facto, the system of continuing linguistic education was established in Russia and still works. However, from the entire spectrum of majors and training profiles, this paper focuses only on those which in my opinion for some above-mentioned reasons; create the most optimal conditions for the training of pedagogical staff in the field of foreign languages (Fig. 1). 


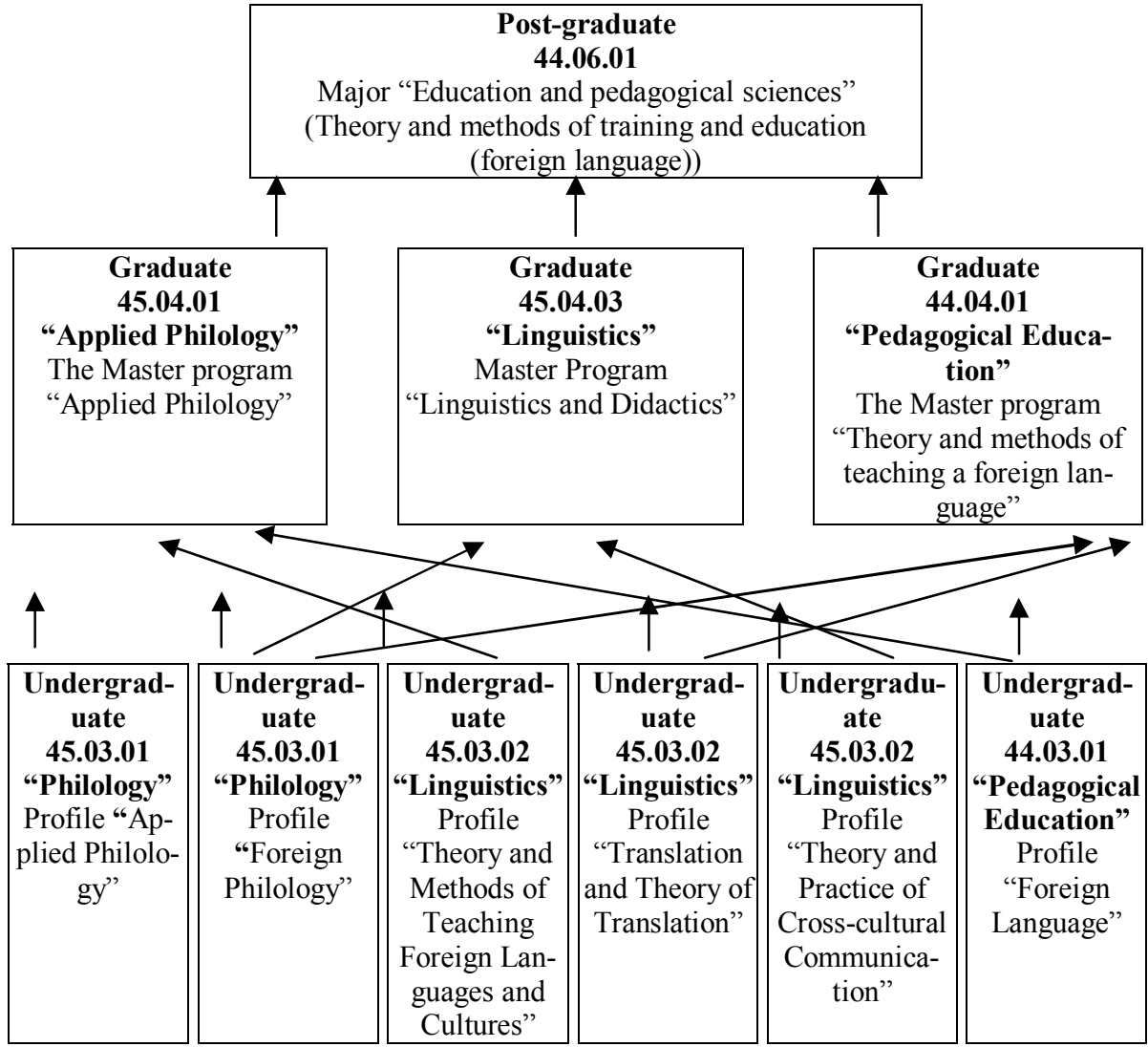

Fig. 1. Model of continuing methodical preparation of teachers

The three-level model of education creates the conditions for a particular academic mobility of students in the selection of majors and programs of a higher level. Thereby, everyone will be able to choose an educational path which will allow him most to be the popular expert in modern labor market. As for pedagogical activity in the field of foreign languages, there are several options which are caused by two main reasons. Firstly, all three linguistics and philology majors considered in this paper at the level of the undergraduate provide students the formation of foreign language communicative competence to the $\mathrm{B} 2 / \mathrm{C} 1$ level. Secondly, in our country there is no regulation limiting the set on graduate with a non-core undergraduate (not related by their professional orientation to graduate in philology, linguistics, or teacher education). Based on the professional activities identified in the Federal Educational Standard of Higher Education and learning content within the basic professional educational program, ideal educational paths to teacher training and foreign language teaching are: a) undergraduate in the major "Linguistics" (profile "Theory and Methods of Teaching Foreign Lan- 
guages and Cultures"), graduate in the major "Linguistics" program "Linguistics and Didactics", post-graduate in major "Education and Pedagogical Sciences" (profile "Theory and Methods of Training and Education"); b) undergraduate in major "Philology" (profile "Applied Philology"), graduate in the major "Philology" (program "Applied Philology"), post-graduate in the major "Education and Teaching of Science" (profile "Theory and Methods of Training and Education"); c) undergraduate "Teacher Education" (profile "Foreign Language"), graduate "Teacher Education" (program of "Theory and Methods of Teaching Foreign Languages"), post-graduate in the major "Education and Teaching of Science" (profile "Theory and Methods of Training and Education"). In addition, cross variant of the transition from the undergraduate to the graduate (from Applied Philology in Linguistics (theory and methods), etc.) are possible; it depends on what majors and related master's programs are developed and were accredited in a particular university. Any combination of the three above-mentioned linguistic majors (programs) create the most optimal conditions for the training of teachers and the teaching of foreign language as in the undergraduate students receive a total psychological and pedagogical and methodological training which is mainly applied to the secondary school. In the graduate the range of the studied issues extends to methods of teaching foreign language in universities.

Those students who completed undergraduate programs of other profiles in language majors ("Philology" (profile "Foreign Philology"), "Linguistics" (profile "Translation and Theory of Translation", "Theory and Practice of Intercultural Communication") and non-linguistic majors (e.g. law, economics, international relations (provided that the level of foreign language they speak correspond to the $\mathrm{B} 2 / \mathrm{C} 1$ level) can also continue their education in one of the methodological master's programs. However, in this case they will need to catch up and make up for the amount of psychological and educational training that they did not receive during the study in undergraduate; but which serves as a basis of master's program in the theory and methods of teaching a foreign language.

Introducing the chain of realization of continuing pedagogical education in the field of foreign languages "bachelor, master and postgraduate school", we are not saying that it is the sole and universal model containing a few options. In this paper the author presented ideas for discussion which regard the most optimal path of teacher training and foreign language teachers based on the contentious issues of domestic law and personal factors of educational programs in the field of developers.

\section{References}

1. Gershunsky, B.S. (1997). Philosophy of education for XXI century (in the search of a practice-oriented educational concepts). Moscow. 
2. (2014). Federal Educational Standard of Higher Education in the major 45.03.01 "Philology" (undergraduate level). Moscow.

3. (2014). Federal Educational Standard of Higher Education in the major 45.03.02 "Linguistics" (undergraduate level). Moscow.

4. (2016). Federal Educational Standard of Higher Education in the major 44.03 .01 "Teacher Education" (undergraduate level). Moscow.

5. (2015). Federal Educational Standard of Higher Education in the major 45.04 .01 "Philology" (graduate level). Moscow.

6. (2015). Federal Educational Standard of Higher Education in the major 45.04 .03 "Fundamental and Applied Linguistics" (graduate level). Moscow.

7. (2015). Federal Educational Standard of Higher Education in the major 44.04 .01 "Teacher Education" (graduate level). Moscow.

8. Galskova, N.D. and Gez, N.I. (2009). Theory of teaching foreign languages. Didactics and methods. Moscow: Academia.

9. Safonova, V.V. (2016). Important issues of methodical training of post-graduate students in the context intercultural language education paradigm (linguistic university/linguistic faculties). Foreign languages in school. 3.

Resived 02.09.2016.

\section{Information about the author}

Sysoyev Pavel - Doctor of pedagogical sciences, Professor, Head of the Department of linguistics and language didactics at Derzhavin Tambov State University, professor at the Department of Foreign Languages of Moscow State Pedagogical University (Tambov, Moscow, Russian Federation). E-mail: psysoyev@yandex.ru 